\title{
Mode of Transmission
}

National Cancer Institute

\section{Source}

National Cancer Institute. Mode of Transmission. NCI Thesaurus. Code C128376.

The process by which an infection is transmitted to a person. 